\title{
A extensão universitária na perspectiva de estudantes de cursos de graduação da área da saúde
}

\author{
University community work from the perspective of the undergraduate students \\ in health degree courses
}

\author{
Marcos Aguiar Ribeiro ${ }^{1}$, Ana Suelen Pedroza Cavalcante ${ }^{2}$, Izabelle Mont'Alverne Napoleão \\ Albuquerque $^{3}$, Maristela Inês Osawa Vasconcelos ${ }^{4}$ \\ 1 Acadêmico. Universidade Estadual Vale do Acaraú (UVA), Brasil. E-mail: marcosaguiar61@hotmail.com \\ 2 Acadêmica. Universidade Estadual Vale do Acaraú (UVA), Brasil. E-mail: anasuelen15@hotmail.com \\ 3 Vice-Reitora. Universidade Estadual Vale do Acaraú (UVA), Brasil. E-mail: izabellemontalverne@gmail.com \\ 4 Pró-Reitora de Extensão. Universidade Estadual Vale do Acaraú (UVA), Brasil. E-mail: miosawa@gmail.com.
}

Recebido em: 31/03/2015 | Aprovado em: 16/03/2016

DOI: 10.12957/interag.2016.15897

\begin{abstract}
Resumo
As universidades, por meio do Ensino, Pesquisa e Extensão, têm a incumbência de produzir conhecimento e assim formar cidadãos e profissionais comprometidos socialmente. Nessa perspectiva, enfatiza-se a relação transformadora entre Universidade e Sociedade, por meio da extensão. A partir do exposto, o objetivo deste estudo exploratório-descritivo foi conhecer as percepções de estudantes sobre a extensão universitária e sua atuação social, participantes de projetos de extensão dos Cursos de Enfermagem e Educação Física de uma Universidade Pública do Interior do Ceará. Utilizou-se o Grupo Focal como método de coleta de informações, que foram posteriormente categorizadas. Assim, identificou-se que a referência que os estudantes possuíam da Extensão estava ligada a democratização do conhecimento, por meio da troca de saberes e do retorno social. Além disso, verificou-se o reconhecimento da extensão como espaço de solidariedade, onde se pode aliar a teoria à prática e se inserir no campo profissional. Entretanto, identificou-se pontos negativos, como pontualidade das ações desenvolvidas, forte vertente assistencialista e falta de recursos financeiros. Nesse sentido, reafirma-se a necessidade da valorização da extensão e de sua indissociabilidade ao ensino e a pesquisa, como forma de garantir uma formação integral que contemplem os três componentes do tripé que sustentam a Universidade.
\end{abstract}

Palavras-chave: Universidades; Relações Comunidade-Instituição; Extensão.

Área temática: Saúde.

\begin{abstract}
The universities, through Teaching, Research and Community work, have the task of producing knowledge and thus forming citizens and socially committed professionals. In this perspective, we emphasize the transformative relation between University and Society by means of community work. Based on that, the purpose of this descriptive exploratory study was to understand students' perceptions of the university community project and its social activities. We took into consideration the perceptions of students who participate in projects for Nursing and Physical Education courses in a state university in the countryside of Ceará. We used the focus group as a method for gathering information, which were subsequently categorized. Thus, we found that the reference that students had concerning community work was related to the democratization of knowledge through knowledge exchange and social return. In addition, there is recognition of community work as an area of solidarity, where you can combine theory and practice to enter the professional field. However, we identified weaknesses, such as scarcely developed actions, strong welfare aspect and lack of financial resources. In this sense, the need of community appreciation is reaffirmed and enhancement of its inseparability from teaching and research as a way to ensure comprehensive training that addresses the three components of the tripod that supports the university.
\end{abstract}

Keywords: Universities; Community-Institutional Relations; Community Work. 


\section{Introdução}

A Constituição Brasileira ${ }^{1}$ traz a educação como um direito de todos e dever do Estado e da família, que visa o pleno desenvolvimento da pessoa, seu preparo para o exercício da cidadania e sua qualificação para o mercado de trabalho. Nesse sentido, a Lei das Diretrizes e Base da Educação Brasileira $(\mathrm{LDB})^{2}$ corrobora ao reafirmar o direito a educação, a partir da Educação Básica e do Ensino Superior.

As instituições de ensino superior são provedoras da formação profissional e educação e têm a incumbência de produzir conhecimento, gerar pensamento crítico, organizar e articular saberes, e formar cidadãos e profissionais². Para tal, alicerça-se no tripé Ensino, Pesquisa e Extensão, constituindo-se como espaço mediador de produção e de difusão do conhecimento. Dessa forma, seu desenvolvimento pressupõe a articulação do trabalho pedagógico em torno de objetivos coesos e coerentes, que tenham por base os processos de democratização do país, os princípios institucionais e os princípios éticos e epistemológicos das atividades-fim da Universidade ${ }^{3}$.

Nesta perspectiva, a Extensão Universitária é o processo educativo, cultural e científico que articula o Ensino e a Pesquisa de forma indissociável e viabiliza a relação transformadora entre a Universidade e a Sociedade ${ }^{4}$. Assim, reafirma-se seu caráter de instituição social educativa, comprometida com as reais necessidades e aspirações da sociedade, atuando decisivamente nas diferentes práticas pedagógicas e políticas contribuindo na construção do perfil do cidadão² .

Explicita-se uma práxis educativa, que enfatiza a necessidade de um currículo dinâmico, flexível e transformador que, por meio de metodologias de ensinoaprendizagem problematizadoras e produtoras de conhecimentos confrontadas com a realidade brasileira e regional, resultem em: democratização do conhecimento acadêmico; instrumentalização do processo dialético teoria/prática; promoção da 
interdisciplinaridade; participação efetiva da comunidade na Universidade; visão integrada do social; e relação transformadora entre Universidade e as demais instâncias sociais $^{5}$.

Assim, a Universidade deve promover a extensão, aberta à participação da população, visando à difusão das conquistas e benefícios resultantes da criação cultural e da pesquisa científica e tecnológica geradas na instituição ${ }^{2}$. Enquanto política educacional, a extensão universitária possibilita aos discentes novos cenários de aprendizagem, aproximando-lhes do contexto social, político e econômico, nos quais tem a oportunidade de aprender a dinâmica das relações de poder que permeiam esse contexto, o que lhes proporciona um conhecimento que se encontra para além dos muros acadêmicos ${ }^{6}$.

A partir do exposto, o objetivo deste estudo foi conhecer as percepções dos estudantes participantes de projetos de extensão do campus de Ciências da Saúde de uma Universidade Pública do interior do Ceará, acerca da extensão universitária e sua atuação social.

\section{Metodologia}

Este é um estudo exploratório-descritivo, sob abordagem qualitativa. As pesquisas exploratórias-descritivas permitem que o pesquisador perceba o fenômeno estudado em toda sua complexidade, de forma a dar visibilidade a um fator social, aumentar aexperiência do pesquisador e possibilitar a descrição dos fatos e fenômenos de uma determinada realidade ${ }^{7}$.

Para $\mathrm{Minayo}^{8}$, a abordagem qualitativa determina uma aproximação entre sujeito e o objeto, o que possibilita o resgate dos motivos, das intenções, dos projetos dos atores, a partir dos quais as ações, as estruturas e as relações tornam-se significativas. Assim, trabalha com o universo dos significados, dos motivos, das aspirações, das crenças, dos valores e das atitudes.

A pesquisa foi realizada no ano de 2014, com dez estudantes dos cursos de graduação em Enfermagem e Educação Física de uma Universidade Pública do Interior do Estado 
do Ceará, que participam de projetos de extensão, regularmente cadastrados na PróReitoria de extensão desta Universidade.

Assim, foram utilizados os seguintes critérios de inclusão: estar regularmente matriculado; ser maior de 18 anos; estar cursando a partir do terceiro semestre da graduação; participar de pelo menos um dos projetos de extensão regularmente cadastrados na Pró-Reitoria de extensão da Universidade; participar a mais de seis meses do projeto de extensão; ter participado de no mínimo uma atividade de extensão fora da Universidade; e aceitar participar do estudo.

Para a coleta de informações utilizou-se o método do grupo focal. Segundo Boccato e Ferreira $^{9}$, o grupo focal é uma técnica de coleta de dados que promove a interação entre os participantes e o pesquisador, cujo objetivo é coletar informações por meio da realização de uma discussão focada sobre temas específicos e diretivos com os objetivos da pesquisa. Dentre seus principais benefícios, destacam-se a possibilidade de capturar respostas das pessoas no espaço e tempo real e a possibilidade de obter a inclusão de participantes que, em uma situação real, não poderiam ser observados diretamente em ação. Além disso, pode-se resgatar um histórico mais rico do tema abordado, uma vez que contará com a participação de diversos atores, em contexto de interações face a face ${ }^{10}$. Foi realizado um encontro, sendo este gravado para análise das informações.

Depois da coleta de informações, as falas foram transcritas e categorizadas. A categorização é uma operação de classificação de elementos essenciais de um conjunto, por diferenciação e, seguidamente, por reagrupamento segundo o gênero, com os critérios previamente estabelecidos ${ }^{11}$. Dessa forma, a categorização tem por finalidade fornecer uma representação simplificada das informações brutas, que passam a ser informações organizadas sistematicamente ${ }^{12}$.

Nesse sentido, a organização das informações resultou nas seguintes categorias: Conceito de extensão; Atividades realizadas pelos Projetos de Extensão; e Limitações e Dificuldades para o desenvolvimento dos Projetos de Extensão.

Vale ressaltar ainda que os participantes concederam aquiescência ao estudo por meio do Termo de Consentimento Livre e Esclarecido, garantindo-lhes seu anonimato e resguardando-lhes o direito de não concluir a participação no estudo se assim 
desejassem. Desta forma, para resguardar os nomes dos participantes, os mesmos foram identificados por nomes de pássaros.

Convém salientar que este estudo foi orientado a partir da Resolução 466/12 do Conselho Nacional de Saúde, que incorpora, sob a ótica do indivíduo e das coletividades, os referenciais básicos da bioética, visando assegurar os direitos e deveres que dizem respeito à comunidade científica, aos sujeitos da pesquisa e ao estado. Assim, obteve parecer favorável pelo Comitê de Ética em Pesquisa da Universidade Estadual Vale do Acaraú, com parecer n ${ }^{\circ} 384.429^{13}$.

\section{Resultados e Discussão}

\section{Conceito de extensão}

Identificou-se por meio das informações obtidas a compreensão que os estudantes tinham acerca da extensão universitária. Assim, as falas a seguir fazem referência ao conceito de Extensão na perspectiva dos participantes do estudo.

\footnotetext{
"A extensão é a organização de ações envolvidas por docentes e discentes em que a universidade contribui com a comunidade" (Coruja).

“[...] uma forma de aproximação da comunidade com a universidade e também uma forma de estabelecer uma troca de conhecimento, dos acadêmicos e a comunidade em si, e também a gente estuda num estabelecimento público e devemos satisfação pra essa população" (Andorinha).
}

Nessa perspectiva, evidencia-se a extensão universitária como prática de troca de saberes sistematizados que têm como consequência, além da produção do conhecimento resultante do confronto com a realidade, a democratização do conhecimento acadêmico e a participação efetiva da comunidade na universidade ${ }^{4}$.

Oliveira e Garcia ${ }^{14}$ corroboram ao afirmar a extensão como um espaço privilegiado para viabilizar a interação do social e institucional, em variadas e ampliadas dimensões. A extensão articula um processo educativo, cultural e científico, ao lado do ensino e da pesquisa, gerado pelas possibilidades e pela força articuladora que está na natureza das ações nascidas das relações sociais e comunitárias. 
Verifica-se também, a partir das falas, a extensão universitária com um espaço de solidariedade.

"Eu sempre gosto muito de fazer alguma coisa boa pra alguém, então a extensão universitária foi uma forma que vi pra dá esse retorno, assim... o retorno a comunidade, retorno de que, nos fazemos parte de um corpo discente de uma universidade pública e sabemos que é a população que paga a luz, que paga essas cadeiras, que paga os professores, então essa mesma comunidade, essa mesma população, ela é carente ainda de muitos tipos de assistência e através da extensão a partir dos conhecimentos que a gente adquire aqui na faculdade a gente pode retornar esses conhecimentos como forma de dar nossa gratidão e realmente fazer um papel na sociedade” (Canário).

Neste sentido, a extensão apresenta no seu arcabouço o compromisso social, uma vez que, segundo Silva ${ }^{15}$, o compromisso com a sociedade tem caracterizado a ação e a reflexão da extensão universitária.

Assim, em um movimento contrário ao que ocorre na lógica da impessoalidade predominantemente característico da vida acadêmica, os projetos de extensão precisam apresentar-se como um espaço de estabelecimento de relações solidárias, baseadas na afetuosidade a fim de aumentarem a teia das relações sociais. O contato com a realidade da comunidade, de seus problemas e saberes, conduz à relativização do saber científico, rompendo com a ilusão de um único saber e das certezas irrefutáveis ${ }^{16}$.

Além disso, a possibilidade de interagir com os conhecimentos compartilhados em sala de aula às práticas profissionais também foi referida para conceituar extensão, o que mostra o anseio que os estudantes têm de atuar logo que possível nos campos profissionais.

\footnotetext{
“[...] extensão é fazer com que além da prática que tem e da teoria, a gente também consiga passar muita coisa para a sociedade da própria formação da gente, fazendo com que a gente fique mais perto do espaço que vamos atuar quando a gente for profissional" (Sabiá).

“[...] nos dá a possibilidade de experienciar atividades profissionais enquanto alunos” (Pica-Pau).
} 
Dessa forma, a extensão constitui-se como elemento de interação entre a universidade e a sociedade, capaz de operacionalizar a relação teoria/prática e promover a troca entre os saberes acadêmicos e populares ${ }^{17,18}$.

Nesse contexto, para os estudantes, a extensão torna-se uma ferramenta importante de inserção no meio profissional. Além disso, promove pró-atividade e autonomia no processo de aprendizagem/desenvolvimento, concedendo oportunidades de conhecimento das realidades locais, possíveis espaços de atuação profissional.

A partir de então, a extensão universitária possibilita a aquisição de conhecimentos que funcionam como um preparatório para a prática profissional; assim, já terão vivenciado aspectos da profissão e antecipado algumas das possíveis dificuldades que serão vivenciadas quando começarem a trabalhar. Além disso, podem alcançar conhecimentos específicos para se tornarem profissionais preparados para atuarem em suas respectivas áreas de formação ${ }^{15}$.

\section{Atividades realizadas pelos Projetos de Extensão}

Verifica-se nas atividades extensionistas realizadas pelos Projetos dos participantes da pesquisa, uma forte vertente assistencialista, que ocorre predominantemente, como se pode observar nos relatos dos participantes.

\footnotetext{
"É trabalhado a reabilitação física através de atividades, exercícios de musculação, ginástica e atividades aquáticas” (Rouxinol).

"No nosso projeto realizamos acompanhamento de gestante adolescente de altorisco" (Coruja).
}

Nesse sentido, Ribeiro ${ }^{16}$ corrobora as afirmações sobre o caráter assistencialista das várias práticas de extensão, tendo como guia principal a prestação de serviços à comunidade, nos próprios espaços acadêmicos, sem qualquer aproximação com a realidade social da população.

Essas ações meramente assistenciais acabam por limitar a própria extensão universitária, que requer uma educação problematizadora em que os sujeitos adentrem na realidade/contexto local, compartilhem o conhecimento apreendido dentro da universidade e absorvam a sabedoria da comunidade em que estão inseridos, 
proporcionando assim a construção dialógica do conhecimento, por meio do saber horizontal.

Dessa forma, a extensão constitui-se como uma prática educativa dialógica, que se propõe a considerar as pessoas envolvidas nas ações, como sujeitos de decisão, de transformação e não como meros receptores de conhecimentos, passíveis à manipulação ${ }^{16}$ e remete ainda à ideia de que o conhecimento se estende desde aqueles que se julgam sabedores até àqueles que se julgam nada saberem ${ }^{19}$.

Assim, a extensão não se deve restringir apenas à prestação de serviços à comunidade, pois descaracterizaria toda a reflexão realizada sobre seu compromisso social e pedagógico.

Verificou-se também que a maioria dos projetos não têm caráter interdisciplinar, com poucas experiências de participação de estudantes de outros cursos de graduação. Neste aspecto, foi reverberado pelos estudantes a necessidade de espaços de construção da interdisciplinaridade entre os cursos de educação física e enfermagem.

\footnotetext{
"A gente estuda um do lado do outro, mas nem parece [...]” (Pardal).

“[...] aqui existe uma cerca elétrica entre o curso de educação física e enfermagem e que nós e principalmente os professores que construíram [...]falta espaços como esse de sentar junto e conhecer o outro, discutir as coisas, seilá [...]” (Pelicano).
}

Mastelaro et al ${ }^{20}$ colaboram ao afirmar que na práxis extensionista a falta do caráter interdisciplinar representa uma limitação a ser superada, de forma a interferir na atuação social e na produção do conhecimento. Nessa perspectiva, a interdisciplinaridade pode ser caracterizada com a interação de modelos e conceitos, de material analítico e de metodologias, buscando uma consistência teórica e operacional que estruture o trabalho dos atores do processo de extensão. Frente à complexidade e dimensão das questões a serem abordadas, a interdisciplinaridade se impõe como diretriz básica desse processo. A prática dessa interdisciplinaridade e da interação com outros setores conduz à interprofissionalidade e à intersetorialidade e ao desenvolvimento das relações interpessoais ${ }^{21}$.

Destaca-se também que muitas atividades são de inconstante realização ou de caráter somente de difusão cultural, pois ocorrem pontualmente. No entanto, pode-se afirmar 
que as ações seriam mais efetivas se garantissem uma certa longitudinalidade do processo educacional, uma vez que, segundo Leão ${ }^{22}$, a educação e a aprendizagem não são um conjunto pontual de eventos institucionais, pois são contínuas e acumulativas, que devem também instigar o protagonismo social dos indivíduos envolvidos nas ações. O relato a seguir mostra-se consoante com o exposto.

“[...] realizamos ações nas praças e entrega de panfletos em comemoração a eventos, tipo o Outubro Rosa” (Bem-te-vi).

Vale salientar ainda, a partir das falas, que as atividades desenvolvidas por alguns projetos não incorporam a comunidade em sua realização, com a participação apenas de estudantes, o que rompe com o conceito proposto pelo Plano Nacional de Extensão, no qual se afirma que na extensão deve haver a participação efetiva da comunidade na atuação da universidade? ${ }^{2}$.

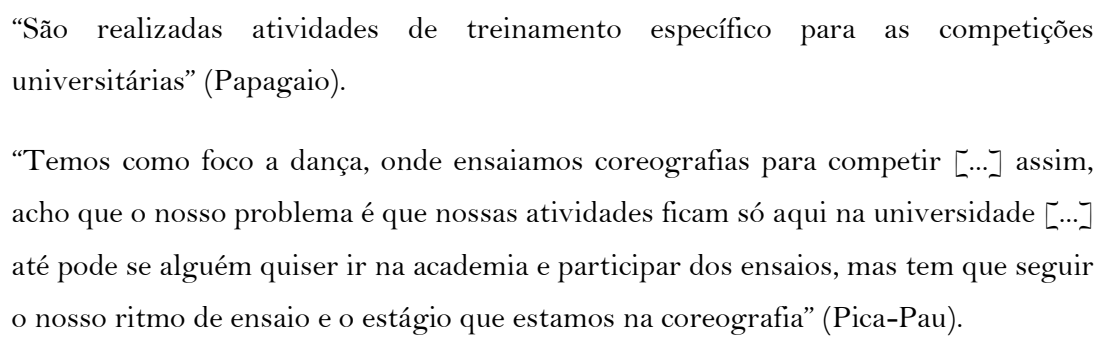

Entende-se ainda que, essa interação entre os saberes acadêmicos e populares fortalecem a organização universitária e a sociedade ${ }^{23}$. Assim, a construção do conhecimento pautada em uma troca contínua entre estes saberes potencializará os diferentes espaços sociais.

Em um estudo realizado com participantes do projeto de extensão Roda de debate sobre crack, outras drogas e vulnerabilidades associadas na Universidade de Brasília, verificou-se por meio de questionários e entrevistas semiestruturadas, que é necessário ampliar e aprimorar a extensão universitária, de forma a oferecer um caminho aberto para a circulação e compartilhamento de conhecimentos, experiências e vivências entre a comunidade e a universidade. Assim, a extensão constitui-se como um espaço de desenvolvimento e estímulo ao conhecimento a partir da reflexão, crítica e intervenção ${ }^{24}$. 
Com isso, infere-se a prática da extensão universitária como um meio e processo de transformação da formação a partir da imersão comunitária. Todavia, faz-se necessário o acompanhamento contínuo das atividades dos extensionistas, de forma a possibilitar a sistematização dos conhecimentos compartilhados na comunidade, garantindo, assim, a interlocução entre as experiências vivenciadas na extensão e a prática do ensino e da pesquisa.

\section{Limitações e Dificuldades para o desenvolvimento dos Projetos de Extensão}

Ao serem questionados sobre as limitações e dificuldades enfrentadas no desenvolvimento das atividades de seus Projetos de Extensão, os participantes do estudo, em sua maioria, afirmaram que a falta de recursos financeiros corrobora no que concerne à execução das atividades e à sustentabilidade dos projetos, como se pode identificar a seguir:

"Não disponibiliza material, não tem material, isso é a realidade... as aulas de futsal são usadas bola de handball. Quando tem bola de futsal são doadas pela prefeitura ou temos que comprar do nosso bolso” (Pelicano).

Essa situação explicita a desvalorização e o pouco investimento atribuído à extensão universitária. A extensão que deveria ser vista como uma das ações formadoras indissociáveis que compõem o tripé da universidade acaba sendo relegada a uma posição de inferioridade no espaço universitário. Enquanto os docentes e discentes pesquisadores se ocupam de projetos de pesquisas e consequentes publicações como forma de atrair financiamentos, os extensionistas veem a extensão como uma atividade que conceitualmente se destina a inserir o formando na realidade social, ao mesmo tempo em que abre um viés de acessibilidade do conhecimento científico à sociedade ${ }^{25}$.

Em estudo realizado em um centro universitário, identificou-se que a bolsa da iniciação científica é mais valorizada financeiramente do que a da extensão, uma vez que os valores repassados aos estudantes das diferentes modalidades de bolsas são divergentes, sendo maiores para os que realizam as atividades de iniciação científica ${ }^{26}$. 
Além da barreira financeira, alguns participantes enfatizaram questões que envolvem aspectos relacionados ao interesse, assiduidade e disponibilidade.

“[...] nossas agendas e horários não se batem, além de alguns alunos que não tem compromisso e acabam faltando demais" (Papagaio).

Nessa perspectiva, as limitações na participação dos discentes refletem negativamente nas atividades de extensão, uma vez que o universitário deve colocar-se em papel fundamental na organização das atividades, de forma a integrar-se na coordenação do projeto e contribuir para a descentralização do planejamento e das decisões e estabelecimento de uma relação mais horizontal entre docentes e discentes ${ }^{16}$.

Por outro lado, os discentes afirmaram que as limitações de participação estão relacionadas ao pouco apoio da Universidade, bem como de alguns docentes, que dificultam e não valorizam a participação em projetos de extensão, que enfatizam somente o ensino da grade curricular e esquecem que a extensão, junto à pesquisa, integra o tripé das universidades.

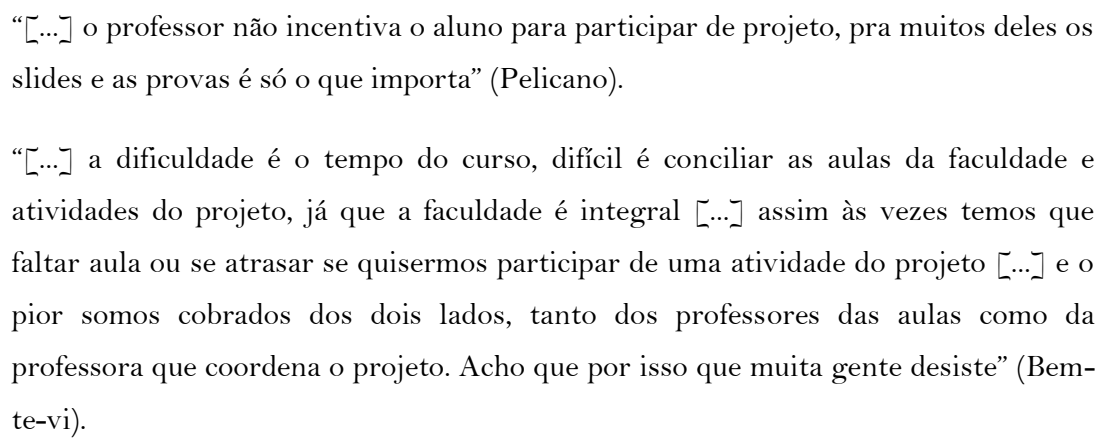

Nesse sentido, reafirma-se a necessidade da valorização da extensão e de sua indissociabilidade ao ensino e a pesquisa, conforme garantido no artigo 207 da Constituição Brasileira1. Assim, a extensão, como prática acadêmica, busca interligar a universidade em suas atividades de ensino e pesquisa com as demandas da sociedade, buscando respeitar o compromisso social da universidade. Dessa forma, a relação entre extensão e pesquisa ocorre, sobretudo, pelo papel que esta passa a desempenhar como (re)criadora de conhecimentos e experiências, além de contribuir para a transformação social $^{27}$. 
Neste ínterim, a extensão universitária distingue-se por constituir um processo metodológico que pergunta pela relevância social do ensino e que procura, por meio da pesquisa, referências objetivas aos problemas reais que envolvem a sociedade. Assim, pondera-se ao afirmar que uma sólida formação universitária é uma das maiores contribuições da universidade para a sociedade. Diante disso, decorre a necessidade da extensão ser entendida como extensão da pesquisa e do ensino ${ }^{6}$.

\section{Considerações Finais}

Para os estudantes de enfermagem e educação física, participantes da pesquisa, a extensão universitária pode ser compreendida como: ação/intervenção social de resposta da universidade para a sociedade; devolutiva dos conhecimentos apreendidos na academia a partir de ações de compartilhamento entre o saber científico e o saber popular; mecanismo de preparação e aproximação do futuro campo profissional; e ação solidária de compromisso com a comunidade.

Dessa forma, essas percepções se complementam, uma vez que permitem o avanço da concepção de extensão universitária enquanto ação política, social e cultural de resposta às necessidades da comunidade. Considera-se a necessidade da extensão universitária propiciar a integração com a comunidade, de forma a contribuir com o processo de formação de um profissional comprometido com a realidade social.

Além disso, vale salientar a relevância da extensão para a formação acadêmica, haja vista o desenvolvimento da consciência profissional e da responsabilidade cidadã. Todavia, é necessário acompanhar e avaliar permanentemente a prática extensionista, de forma a romper com a concepção de um simples espaço de disseminação de conhecimentos disciplinares, assistencialismo e prestação de serviço e difusão de eventos culturais.

Assim, faz-se necessário dimensionar a extensão como uma parte integrante da formação, indissociável e não menos importante que o ensino e a pesquisa, de forma a compreender e reverberar em suas práticas o seu caráter político, social e científico. 
Verifica-se a necessidade de estudos que analisem os impactos das ações extensionistas nas comunidades, de maneira a desvelar as contribuições para a comunidade e para a formação acadêmica.

\section{Contribuição dos autores}

Marcos Aguiar Ribeiro e Ana Suelen Pedroza Cavalcante participaram da concepção e de todas as etapas de produção do manuscrito. Izabelle Mont'Alverne Napoleão Albuquerque participou na orientação da pesquisa e na produção final do manuscrito. Maristela Inês Osawa Vasconcelos participou da revisão final do manuscrito.

\section{Nota dos autores / Conflito de interesses}

Este manuscrito não apresenta nenhum tipo de conflito de interesse. Além disso, obteve parecer favorável do Comitê de Ética em Pesquisas com Seres Humanos da Universidade Estadual Vale do Acaraú. Ademais, esta pesquisa está vinculada as atividades do Módulo Práticas Interdisciplinares do Curso de Enfermagem.

\section{Referências}

1. BRASIL. Constituição (1988). Constituição da República Federativa do Brasil de 1988. Brasília: Congresso Nacional, 1988.

2. BRASIL. Ministério da Educação. Lei nº 9.394, de 20 de dezembro de 1996. Estabelece as diretrizes e bases da educação nacional. Brasil: Ministério da Educação, 1996.

3. SANTA CATARINA. I Conferência de Ensino, Pesquisa e Extensão (COEPE). Chapecó: Universidade Federal da Fronteira Sul, 2010.

4. BRASIL. Ministério da Educação. Secretaria de Educação Superior. Plano nacional de extensão. Ministério da Educação. Brasília. 1999.

5. BRASIL. Indissociabilidade ensino-pesquisa-extensão e a flexibilização curricular: uma visão da extensão. Fórum de Pró-Reitorias de Extensão das Universidades Públicas Brasileiras. Porto Alegre: UFRGS, 2006. 100 p. 
6. SANTOS, Marcos Pereira. Contributos da Extensão Universitária brasileira à formação acadêmica docente e discente no século XXI: Um debate necessário. Revista Conexão UEPG, Paraná, v. 6, n. 1, p.10-15. 2010.

7. TRIVIÑOS, Augusto Nibaldo Silva. Introdução à pesquisa em ciências sociais: a pesquisa qualitativa em educação. 1.ed. São Paulo: Atlas, 1987. 175 p.

8. MINAYO, Maria Cecília de Souza. (Org). Pesquisa social: teoria método e criatividade. $29^{\mathrm{a}}$. Edição. Petrópolis: Vozes, 2010.

9. BOCCATO, Vera Regina Casari; FERREIRA, Estela Maris. Estado comparativo entre grupo focal e o protocolo verbal em grupo no aprimoramento de vocabulário controlado em fisioterapia: uma proposta metodológica qualitativa-cognitiva. InCID:

R. Ci. Inf. e Doc., Ribeirão Preto, v. 5, n. 1, p. 47-68, mar./ago. 2014.

10. CRESWELL, John W. Projeto de pesquisa: métodos qualitativo, quantitativo e misto. Porto Alegre: Artmed, 2007. 248p.

11. BARDIN, Laurence. Análise de conteúdo. Lisboa: Edições 70, 1977.

12. BARDIN, Laurence. Análise de conteúdo. Lisboa: Edições 70; 2008.

13. BRASIL. Ministério da Saúde. Conselho Nacional de saúde. Resolução 466/12. Brasília: Ministério da saúde, 2012.

14. OLIVEIRA, Therezinha Maria Novais de; GARCIA, Berenice Rocha Zabbot. A extensão e o seu papel na formação acadêmica. Revista Univali, Itajaí, v.14, n.1, p.111117 , jun. 2009.

15. SILVA, Aurelio Rodrigues. A Contribuição da Extensão na Formação do Estudante Universitário. Universidade Católica de Brasília: Distrito Federal, 2011. $97 \mathrm{f}$.

16. RIBEIRO, Kátia Suely Queiroz Silva. A experiência na extensão popular e a formação acadêmica em fisioterapia. Cad. Cedes, Campinas, v. 29, n. 79, set./dez, p. 335-346. 2009.

17. BRASIL. Ministério da Educação. Secretaria de Educação Superior. Fórum de Pró-Reitores de Extensão das Universidades Públicas Brasileiras. Universidade Federal de Minas Gerais - PROEX. COOPMED Editora, 2007. 
18. CRUZ, Safira Rios Souza; et al. Extensão Universitária: Um Caso de Ação Voltada ao Desenvolvimento Social em Saúde Pública. Cadernos de Graduação - Ciências Humanas e Sociais, Aracaju, v. 1, n.16, p. 127-134, mar. 2013.

19. FREIRE, Paulo. Extensão ou comunicação? 13. ed. São Paulo: Paz \& Terra, 1977.

20. MASTElaro, Catarina; OTERO, Guilherme Arosa Prol; BRAGA, Renata dos Santos; FIRBIDA, Thiago de Paula; SANTOS, Thiago Haruo. Extensão em relações internacionais:por uma nova práxis. Revista Direito \& Sensibilidade, São Paulo, v.1, n.1, p.29-40. 2011.

21. CORRÊA, Edson José. Extensão Universitária, política institucional e inclusão social. Rev. Bras. Extensão Universitária, v.1, n.1, p.12-15, jul-dez. 2003.

22. LEÃO, Marluce Auxiliadora Borges Glaus. Educação permanente de adultos maduros, idosos e de profissionais da área do envelhecimento: fundamentos para um projeto pedagógico de extensão universitária. Revista de Extensão da Universidade de Taubaté, Taubaté, v. 1, n. 1, p.45-54. 2008.

23. VIERO, Tatiane Vedoin. Programa de Extensão Universitária: Perspectivas de Inclusão Social e Formação de Professores. Revista Didática Sistêmica, v. 14, n. 2., p.30-45, ago-set. 2012.

24. SILVA, Maria de Nazareth Rodrigues Malcher de O. Silva et al. Incluindo a Temática de Drogas e Vulnerabilidade Social na Formação Profissional por meio de Ações de Extensão: o Caso da Universidade de Brasília, Campus Ceilândia. Rev. Cult. e Ext. USP, São Paulo, v. 11, n. 1, p. 31-40, set. 2014.

25. SILVA, Rosemary Ferreira da; ROSA, Marise Marçalina de Castro Silva. Extensão universitária no currículo das licenciaturas: inovação e relação de sentido. Olhar de professor, Ponta Grossa, v. 14, n. 2, p. 371-380, 2011.

26. RODRIGUES, Ângela Ribeiro. A extensão universitária: indicadores de qualidade para avaliação de sua prática: Estudo de caso em um centro universitário privado. Florianópolis: UFSC, 2003. 182 p.

27. BRETAS, José Roberto da Silva; PEREIRA, Sônia Regina. Projeto de extensão universitária: um espaço para formação profissional e promoção da saúde. Trab. educ. saúde, Rio de Janeiro, v. 5, n. 2, p.1-11, jul. 2007. 